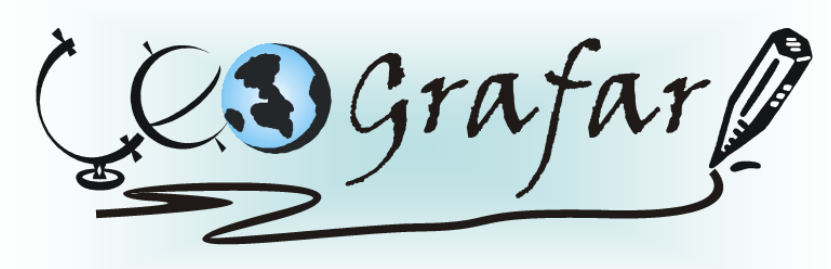

Revista Eletrônica do Programa de Pós-Graduação em Geografia - UFPR

\title{
TERRITÓRIO: UMA COMBINAÇÃO DE ENFOQUES - MATERIAL, SIMBÓLICO E ESPAÇO DE AÇÃO SOCIAL.
}

\author{
CARLA HOLANDA DA SILVA ${ }^{1}$
}

\begin{abstract}
Resumo: O presente artigo tem como temática uma recapitulação do conceito de território, desde seu significado etimológico, passando por suas raízes evolução na ciência geográfica, caminhando para uma discussão do conceito em outras ciências sociais. A discussão aqui estabelecida pretende abordar aspectos materiais, referência ao Estado-Nação discutida por Claude Raffestin (1993), o enfoque simbólico e também material, que retrata duas dimensões do território, a do pensamento e a do desejo exposta por Deleuze e Guattari (1996;1997), finalizando a discussão na abordagem do território como um espaço de Ação Social abordado por Antony Giddens ( 1991). Tal arcabouço teórico foi utilizado como base para o desenvolvimento da dissertação de mestrado intitulada "O encontro de territorialidades na diáspora: Japoneses e Nordestinos em Assaí-PR." A mesma, buscou discutir encontros de territorialidades de grupos migrantes distintos e com identidades culturais marcantes em um território comum, o município de Assaí. Dessa maneira, nesse artigo procurou-se estabelecer uma discussão teórica acerca do conceito de território proposto por diferentes autores e sobre enfoques distintos, que não são restritos apenas ciência geográfica, mas discutem em outras áreas do saber.
\end{abstract}

Palavras-Chave: território; material-simbólico; pensamento-desejo; espaço social.

\section{TERRITORY: A COMBINATION OF APPROACHES - MATERIAL, SYMBOLIC AND SPACE OF SOCIAL ACTION.}

\begin{abstract}
The present article has as thematic a recapitulation of the territory concept, since its meaning etimology, passing for its roots evolution in geographic science, walking for a quarrel of the concept in other social sciences.The quarrel established here intends to approach aspects, reference to the State-Nation argued for Claude Raffestin (1993), the symbolic and also material approach material, that portraies two dimensions of the territory, of the thought and of the desire displayed for Deleuze and Guattari (1996), finishing the quarrel in the boarding of the territory as a boarded space of Social Action for Antony Giddens (2003). Such theorethical base was used as base for the development of the master's degree dissertation of intitled "the meeting of territorialities in the diáspora: Japanese and Northeasterns in Assaí-PR."The same one, searched to argue meeting of territorialities of distinct migrantes groups in a common territory, the city of Assaí. In this way, it was looked to construct a theoretical apparatus that it aimed at to give to base the realities observed in the field and at the same time to allow the conversation of different approaches of the concept of territory considered for theoreticians that they are not restricted only geographic science, but argue in other areas of knowing.
\end{abstract}

Key-Words: territory; material-symbolic; thought-desire; social space.

\footnotetext{
${ }^{1}$ Bolsista CNPq-REUNI - Doutoranda em Geografia
} 


\section{INTRODUÇÃO}

O presente artigo é uma reflexão teórica sobre diferentes enfoques do território que são passíveis de conversação, desde o enfoque material que aborda a concepção de Estado-Nação e está pautada em teóricos como Claude Raffestin (1993), o enfoque simbólico e também material, que retrata duas dimensões do território a do pensamento e a do desejo tratada por Deleuze e Guattari (1995, 1996, 1997), findando-se na abordagem do território como um espaço de Ação Social abordado por Antony Giddens (1991; 2003). Esses enfoques encontram se em uma rede teórica, na qual o conceito de território se configurou como o ator principal.

Assim, o mesmo artigo tem como objetivo propor uma arquitetura teórica que aborde diferentes aspectos do território. O mesmo trabalho é parte do resultado teórico da dissertação de mestrado, apresentada no ano de 2008, que tem como título "O encontro de territorialidades na diáspora: Japoneses e Nordestinos em Assaí-PR.” A mesma, buscou discutir encontros de territorialidades de grupos migrantes distintos em um território comum, o município de Assaí, e para tal, realizou-se a construção de um arcabouço teórico relevante que teve como uma de suas bases o conceito de território explorado na ciência geográfica e também em outras ciências sociais.

Assim, o artigo se apresenta inicialmente destacando uma retomada do conceito de território na ciência geográfica, na qual se busca suas raízes etimológicas e suas raízes e evolução na ciência geográfica, de modo que ao mesmo tempo seja estabelecida uma intensa relação com outras áreas do saber.

Posteriormente, desenvolveu-se uma discussão acerca do território e da territorialidade sob o olhar de Claude Raffestin, na qual foram abordadas discussões entorno de poder e as relações que esse impõe no território para a própria definição da territorialidade. A seguir, destaca-se a abordagem de Gilles Deleuze e Felix Guattari, (1995, 1996, 1997) na qual o território é discutido sob o enfoque de pensamento e desejo, ou seja, material e simbólico. Posteriormente, relacionou-se o enfoque destacado por Giddens (1991; 2003) ao território como um espaço de ação, no qual se concretiza o subjetivo (intencional) e o objetivo racional, construindo relações de poder com estrutura social e estrutura cultural.

Contudo, estabeleceu-se uma teoria a fim de retomar o conceito de território na ciência geográfica e fazer a sua releitura e aplicação a outras concepções de teóricos que não 
pertencem apenas a ciência geográfica, mas as ciências sociais. Assim, buscou-se ao longo do artigo desenvolver uma concepção de território identitário, haja vista que, a forte interligação da identidade com o território é uma relação característica da modernidade e do EstadoNação.

\section{O CONCEITO DO TERRITÓRIO - O "RESSURGIMENTO" DO OLHAR GEOGRÁFICO NAS CIÊNCIAS SOCIAIS}

Cada encontro social seja entre pessoas, grupos sociais e/ou etnias e até a aglutinação num Estado-Nação, forma e desenvolve uma disposição espacial num determinado território. Na modernidade, o território identitário é um tipo territorial relativamente novo. Parte da idéia de uma sociedade de massa que está baseada na configuração de forças políticas e culturais em conjunto. Destarte, poderia ser interpretado como o resultado da superposição de antigas territorialidades que se reúnem numa nova configuração. Significa que o motor da territorialidade é a própria "identidade", um posicionamento social dentro e para fora do território.

Originalmente, a discussão do território surgiu na geografia política do século XIX (na época da consolidação dos Estados-Nações) e definiu o território como um espaço de poder demarcado, controlado e governado e, assim, fixo. $\mathrm{Na}$ atualidade, todavia, atribui-se nova importância ao território por meio da mobilização das fronteiras por ações internacionais, interétnicas e interpessoais. Em consequiência disto, surgiram inúmeras fragmentações. Tratase de uma evolução para territórios em movimento. Haesbaert, em sua destacada obra "O mito da desterritorialização" (2004), expõe brevemente o reaparecimento da discussão territorial baseado na obra de alguns filósofos e cientistas sociais.

De acordo com Haesbaert (2004, p. 26)

É como se a dimensão geográfica ou espacial da sociedade fosse de um momento para o outro "redescoberta" pelas outras ciências sociais, paradoxalmente, porém, mais para afirmar seu enfraquecimento e, em relação ao território, até mesmo seu desaparecimento, do que para demonstrar sua relevância.

O reaparecimento do "território" adquire nas ciências sociais maior ênfase com as 
discussões acerca da "pós-modernidade", Estes apontam parcialmente para um (re)fortalecimento da categoria do espaço em detrimento do tempo ressaltando principalmente as divergentes e desiguais transformações dos territórios. A questão da história, que na modernidade era vista como temporalidade homogênea e linear, uma "narrativa evolucionária" conforme Giddens (1991, p. 15), transforma-se hoje num desencaixe das categorias de espaço e de tempo através da multiplicidade reticular das evoluções (p. 58). Assim, a simultaneidade de diferentes situações paralelas resultam em um novo enfoque sobre o espaço. Neste contexto, o conceito do território mostra-se como dimensão problemática e não-evidente na sociedade pós-moderna e induz novas abordagens teóricas. Porém, estas não se referem apenas às transformações geradas pela reprodução e acumulação do capital, mas também sob enfoques culturais que destacam o conceito do território com novas leituras simbólicas (HARVEY, 1992, JAMESON 1996).

Surgem aí, no hiato entre territórios políticos (fixos) e fluxos simbólicos, sociais e econômicos (SANTOS 1994, p. 272), leituras que se dirigem para um outro viés do território, o da "desterritorialização". No cenário das ciências sociais desenvolve-se agora um debate sobre o possível desaparecimento do território enquanto uma manifestação fixa. Assim, Haesbaert (2004, p.27) coloca que

Muitos filósofos, sociólogos e antropólogos, que há varias décadas ignoravam e/ou criticavam leituras geográficas ou sobre a territorialidade humana, redescobrem a importância da dimensão espacial da sociedade - agora, porém, notadamente, a fim de diagnosticar a polêmica desterritorialização "moderna" - ou "pós-moderna" - do mundo.

Nesta perspectiva, estudiosos como Gilles Deleuze e Felix Guattari argumentam em favor de uma reconstrução espacial completa, com as respectivas des - e reterritorializações (1991 p. 113; também HAESBAERT, 2004, p.28). Alguns autores optam apenas para a abolição dos territórios. Assim, Bertrand Badie expôs no seu livro "La fin des territoires" o fim dos territórios nacionais como foco principal de uma análise política (1995, apud HAESBAERT, 2004, p.28) e Paul Virilio fala em seu livro "O espaço crítico" sobre a hegemonia atual do "espaço-velocidade" que não se define mais como substancial e extensivo, mas acidental e intensivo (1993, p. 81/82; também HAESBAERT, 2004, p.28).

\footnotetext{
${ }^{2}$ Considera-se aqui como pós-modernidade um processo que acentua características da modernidade e não como ruptura com o que estava proposto, mas a sua própria continuidade.
} 
Mas todos estes autores, dentre outros, destacam principalmente a questão da desterritorialização como mero processo fluido.

Entretanto, o próprio Felix Guattari, junto com Raquel Rolnik, atenta que a desterritorialização deve ser discutida enquanto "dimensão - imprescindível - da criação de territórios...” e não como uma “... finalidade em si mesma” (apud HAESBAERT, 2004, p.28). Nesse sentido, o processo de desterritorialização sempre precede um outro território, logo se trata também de um processo de territorialização. Assim, os processos territoriais políticos e sociais coincidem com outros processos de territorialização (simbólicos, ideários) e não podem ser analisados como um fato isolado (veja também DELEUZE/GUATTARI 1996, p. $37)$.

Conseqüentemente, desenvolveu-se este artigo pautado no aspecto da convivência entre diferentes formações espaciais no e do território, embasado na própria discussão da desterritorialização e reterritorialização. Muitas vezes, a convivência pós-moderna é originada e formada através de processos migratórios, processos que envolvem uma desterritorialização (saída da terra de origem) e uma reterritorialização (fixação na nova terra - terra de chegada).

Estes processos são principalmente característicos na formação dos territórios durante a época do colonialismo. Nela, os processos configurativos se apresentam em duas facetas: uma é a formação e consolidação do Estado-Nação, principalmente entre os poderes coloniais e a outra é a formação das colônias e suas posteriores "emancipações" e "independências". Nesta situação, a formação territorial sempre é permeada por relações de poder destas antigas relações que se reproduzem e delimitam estes novos territórios deixando surgir diásporas, às vezes poderosas, às vezes minoritárias, como instrumentos agenciadores do território. Assim, hoje o território político é igualmente produto da ação social e do significado simbólico. Principalmente na fase da crescente democracia e interdependência, estes aspectos sociais e simbólicos ganham maior força diante da construção dos territórios do Estado-Nação.

Para iniciar a presente discussão, investigou-se primeiro o termo "território" no sentido original da palavra. Pois, conforme Haesbaert, (2004, p.42), a raiz etimológica da palavra "território", como apresentada por alguns dicionários, remete ao domínio da terra, direito de posse. Esta materialização é sustentada por uma relação emocional, quanto ao sentimento de terror, aterrorizar, ameaçando qualquer pessoa que vem de fora para este território. Esta duplicidade material-emocional permite, desde longo tempo, certa ambigüidade na interpretação do "território". 
Surge ainda, entre a materialidade e a emoção, a questão simbólica que conforma o domínio via uma representação e restringe o terror e o medo por meio de relações simbólicas. Esta visão simbólica se realiza sob o aspecto emocional, pelo sentimento de pertencimento e é fortemente carregado com um elemento representacional. Destarte, esta categoria representacional faz parte da territorialidade também como categoria psicológica. Assim, podemos compreender que a palavra território incorpora um sentido tríplice que muito foi e continua sendo explorado pelas ciências sociais, especialmente pela geografia.

Os diferentes enfoques do território são também resultados de uma longa discussão do conceito na ciência geográfica, pois o mesmo foi aplicado de diferentes formas. Surge como conceito herdado das ciências naturais, quando representa tanto um espaço positivo para a construção do ego, do self como um espaço negativo em relação a outros indivíduos, pois se trata de um

....elemento geográfico dentro dos limites, nos quais a presença permanente ou freqüente de um sujeito exclui a presença simultânea de outros sujeitos.... Os comportamentos que se fundam na exclusão aderecem-se tanto aos indivíduos como a outras espécies" (Di MEO 1998, p. 42, trad. W.-D. Sahr)

Durante muito tempo, esta visão darwinista da dominação exclusiva do território dificultou bastante a aplicação do conceito para uma geografia humana moderna que se apresenta com um foco na análise do espaço relacional e social. Nele, o conceito do território é um local onde se legitimam relações de poder ou relações sociais em função de um objetivo, seja ele de ordem política, econômica e/ou cultural.

Sob essa perspectiva, a categoria território, quando apareceu inicialmente na "Geografia Política" de Friedrich Ratzel, apontou como elemento essencial o Estado-Nação como símbolo de exclusividade, ou seja, uma área que deveria garantir o poder de um determinado grupo. Discutindo, como Ratzel o fez, o “espaço vital”, contudo, já representa uma visão mais avançada, porque compreende o espaço como um lugar de equilíbrio dinâmico "entre a população de uma dada sociedade e os recursos disponíveis para suprir suas necessidades", definindo assim suas condições de progredir e expandir-se (MORAES, 1998, p.56). Conforme Costa (1991, p. 23, grifo nosso), tratava-se de 
... um território que, com sua população, fronteiras, recursos naturais, etc., se constitua no suporte fundamental para o desenvolvimento de uma dada nação e o fortalecimento de dado Estado.

Posteriormente, com as mudanças epistemológicas da geografia, o conceito do território caminha para outras abordagens, passando por enfoques mais descritivos e menos analíticos do espaço geográfico e por análises do sistema capitalista que levantaram de novo a questão territorial (VALVERDE, 2004, p.120). Assim, as constantes transformações das relações sociais presentes no território permitiram que o mesmo deixasse de estar atrelado apenas à concepção de Estado-Nação, mas como coloca Santos (1994, p.15), mostrando uma "dialética do mundo concreto", no qual se desenvolve a noção do "Estado territorial para a noção pósmoderna de transnacionalização do território.” Estas relações incluem também abordagens simbólicas e passam a ser fundamentais para o entendimento dos fenômenos de fragmentação ou união entre nações (VALVERDE, 2004, p.120).

Assim sendo, o conceito do território acompanha as modificações reais do sistema político mundial, o que possibilita que hoje possa ser analisado sob diferentes ângulos. Neste sentido, a função política para o desenvolvimento de um Estado pode ser reinterpretada como significação específica por diferentes populações ou grupos culturais. O Estado, antigamente um corpo coerente, torna-se, hoje um palco espacial da ação, um espaço em constante modificação. Por isso, ele e seu território, de acordo com Santos (1994, p.15), deveriam ser entendidos como “...forma impura, um híbrido, uma noção que, por isso mesmo, carece de constante revisão histórica." Tais enfoques diversificados atribuem ao conceito um caráter inconstante, igual ao próprio território empírico, pois são oriundos das relações de poderes diferentes, das relações simbólicas e das relações emocionais que representam diferentes intenções entre atores sociais (RAFFESTIN, 1993, p. 59).

As relações de poder são geradas por aspectos que podem ser consideradas tanto materiais, pois em casos de encontros diaspóricos pode se tratar de influências econômicas que alguns grupos culturais possuem sobre o todo, quanto de relações não-materiais, com seus aspectos simbólicos, culturais e psicológicos. Inclui-se nesta visão também a perspectiva relacional, como a própria representação que um grupo possui do outro e de si mesmo, que é determinada pelas relações de poder que delimita e permite o interagir dos grupos com suas identidades, representações e ações. 
Sob esse contexto, faz se relevante destacar a visão de Michel Foucault acerca do poder. Para Foucault, as relações de poder não existem como uma "coisa", um objeto que determina indivíduos, mas são relações entre sujeitos heterogêneos, os quais estão presentes em toda a estrutura social. Assim, o poder não pode ser materializado num ponto específico, como o Estado, mas é co-extensivo a todas as relações sociais (FOUCAULT, 1979, p. 248).

Como aponta Machado apud Foucault (1979, p. XIV) para o filósofo francês, os poderes

... funcionam como uma rede de dispositivos ou mecanismos a que nada ou ninguém escapa, a que não existe exterior possível, limites ou fronteiras. Daí a importante e polêmica idéia de que o poder não é algo que se detém como uma coisa, como uma propriedade, que se possui ou não.

Assim, o poder deve ser entendido enquanto um “... feixe de relações mais ou menos organizado, mais ou menos piramidalizado, mais ou menos coordenado" (Foucault, 1979, p. 248). Ou seja, o poder é algo que está aberto a transformações e é mutável. Por isso, a sua análise deve ser realizada por meio das relações que o constroem. Portanto, se desenvolve num processo que se naturaliza, pois se realiza via relações sociais no território como um espaço permanentemente aberto a transformações.

Conseqüentemente, precisamos esclarecer algumas facetas que as relações sociais atribuem ao conceito do território. Por exemplo, para Boligian e Almeida (2003, p.241), existem duas perspectivas sobre as relações sociais a respeito do território. Uma enfoca o viés político-econômico remetendo a concepção de Estado-nação, no qual se faz referência ao produzir e acumular de capital e de trabalho. A outra está vinculada à esfera simbólica-afetiva ligada às relações sociais existenciais.

Na esfera política-econômica o território representa

... a base espacial onde estão dispostos objetos, formas e ações construídas pelos atores sociais e historicamente determinadas segundo as regras do modo de produção vigente em cada época, ou seja, pelas relações sociais de produção (BOLIGIAN, ALMEIDA, 2003, p.241).

Por outro lado, na perspectiva simbólica-afetiva, o 
Território é o espaço das experiências vividas, onde as relações entre os atores, e destes com a natureza, são relações permeadas pelos sentimentos e pelos simbolismos atribuídos aos lugares. São espaços apropriados por meio de práticas que lhes garantem uma certa identidade social/cultural (BOLIGIAN; ALMEIDA, 2003, p.241).

Assim, as relações de poder são produtoras das relações sociais e de identificações diferentes, opondo relações de produção e relações de vivência.

Para Haesbaert, o conceito do território apresenta uma conotação múltipla mais abrangente, como se refere a uma relação material/funcional e/ou simbólico/igualitária. A conotação material/funcional, ou seja, política/econômica aborda o território como um local “... delimitado e controlado, através do qual se exerce um determinado poder, na maioria das vezes - mas não exclusivamente (destaque C.H. de SILVA) - relacionado ao poder político do Estado" (HAESBAERT, 2004, p. 40). Nesse caso, é atribuído ao território o valor de troca através de relações que envolvam agentes políticos e econômicos, podendo ser público e/ou privado $^{3}$.

Na esfera simbólica/signíca-cultural, todavia, tem-se o território como “...o produto da valorização simbólica de um grupo em relação ao seu espaço vivido" (HAESBAERT, 2004, p.40). Ou seja, essa concepção do território é estabelecida pelo valor de uso, pelo vivido, pela subjetividade, a chamada "identificação positiva" com o local que adquire a mesma força de realidade como as relações de poder abstratas. Assim, pode-se interpretar a ambigüidade do território como múltiplo, diverso, subjetivo e complexo, tanto no lado homogeneizador da globalização como no lado diversificador da cultura (HAESBAERT, 2004, p. 40).

Tanto no discurso de Haesbaert (2004, p. 40) quanto de Boligian e Almeida (2003, p. 241) apresentam-se as relações sociais do território via ações. Estes podem ser coercitivas ou repressivas, mas também um meio de identificação de valores, de sentidos. Assim, o território representa um local que fundamentalmente abrigará uma ou algumas identidades na sua flexibilidade cultural (HAESBAERT, 1999b, p 172).

Sob o aspecto cultural, o território mostra, em qualquer caso, uma característica fluida. Haesbaert o demarca como “... um ato, uma ação, uma rel - ação, um movimento [...] um ritmo, um movimento que se repete e sobre o qual se exerce um controle" (HAESBAERT, 2004, p. 127). Destarte, pode-se compreender a interligação das idéias de Haesbaert com o

\footnotetext{
${ }^{3}$ Nesse caso a referência feita ao poder público remete a figura do Estado e ao poder privado, representado pelas corporações de investimentos particulares.
} 
sociólogo inglês Anthony Giddens. Em "A constituição da sociedade” (2003), Giddens propõe a ação como “... um processo contínuo, um fluxo..." que se realiza na "atividade social cotidiana" (2003, p. 11), sendo presente nas práticas sociais do cotidiano reproduzidas no espaço-tempo, dimensão que o autor define como "co-presença" (p. 4).

A função principal desta conceituação é explicar a produção e reprodução da sociedade como um complexo estruturado. Para Giddens, a estrutura é

... o conjunto de regras e recursos implicados, de modo recursivo, na reprodução social; as características institucionalizadas de sistemas sociais têm propriedades estruturais no sentido de que as relações estão estabilizadas através do tempo e do espaço (GIDDENS, 2003, p. XXXV).

Assim, a teoria da estruturação está pautada na reprodução social, que tem como base as práticas sociais. Giddens (2003, p. 4) define a ação como um ato consciente e motivado. Isto não necessariamente significa que as conseqüências das ações sejam premeditadas ou se efetuam como resultado da intenção. Por isso, além da intencionalidade ou racionalização da ação, Giddens aponta outros dois fatores como fundamentais: a monitoração reflexiva, caso em que a ação tomou um outro rumo e a motivação da ação como um antecedente nãoconsciente (GIDDENS, 2003, p. 4). A monitoração reflexiva pode ser entendida como um controle racionalizado na vida social, já que a motivação da ação refere-se ao potencial da ação e não tanto ao modo que a ação é executada pelo agente. Cada uma utiliza as suas próprias territorialidades, que são diferentes de um simples domínio.

Os três fatores juntos estão presentes no chamado fluxo da conduta humana. Muito embora façam parte deste processo, nem sempre combinam entre si, pois as razões e motivações discursivas de um sujeito podem não estar de acordo com a racionalização posterior da ação devido ao fato que as motivações podem se apresentar de forma inconsciente na conduta humana (GIDDENS, 2003, p. 7).

Com esta teoria, influenciada pelo Freudismo, Giddens liga a questão da ação diretamente ao poder, pois o sujeito tem a possibilidade de atuar de um modo ou de outro definindo os seus poderes ao longo do fluxo da ação. Como as ações estão embutidas na vida cotidiana permite-se ou não (via regras, recursos e legitimações) a execução da ação. Portanto, Giddens entende poder apenas como uma capacidade transformadora que pode ser utilizada. "O poder não é em si mesmo um recurso. Os recursos são veículos através dos quais 
o poder é exercido" (GIDDENS, 2003, p. 17/18). Sob esse contexto, o território representa um espaço de ação que efetiva as relações entre pessoas e ambientes.

Contudo, buscou-se demonstrar nesse primeiro momento do artigo, várias dialéticas do território: uma que se refere à relação entre o espaço fixo e o espaço em formação, como é típico para a (re-)configuração o espaço capitalista e para a sociedade democrática e dinâmica. Uma segunda dialética localiza-se entre os recursos de poder do Estado-Nação e as potencialidades estruturais de relações e ações vividas pelos atores sociais. Neste momento, surge como terceira dimensão a questão simbólica que interliga a representação da individualidade do cidadão com a representatividade dos seus recursos simbólicos.

\section{TERRITÓRIO E TERRITORIALIDADE - A ABORDAGEM DE CLAUDE RAFFESTIN}

As características da multiplicidade do território e a sua formação chamaram, já nos anos 1980, atenção dos geógrafos franceses. Um dos autores que discute, em forma detalhada, o território é Claude Raffestin (1993). Para ele, o território apresenta um caráter relacional e por isso sempre vai além da base material sendo embutido numa complexa rede de relações e ações de indivíduos heterogêneos (HAESBAERT, 2004, p. 82). Tais relações e ações resultam de disputas de forças e confrontos, formando o chamado "campo do poder". Este campo pode ser subentendido como um território, ou seja, um espaço delineado por relações de poder (RAFFESTIN, 1993, p. 53).

Para explicitar o seu entendimento sobre o poder, Raffestin aplica as concepções de Michel Foucault entendendo "poder" como um conjunto de diferentes relações que permeiam determinados lugares (1993, p. 53). Por isso, a concepção não deve ser vinculada exclusivamente à figura de um território fixo, um recurso, mas deveria ser concebida como algo que ultrapasse as barreiras dos territórios materiais através de relações distribuídas por toda a organização social. Neste entender, o poder manifesta-se em relações interpessoais e é extremamente flexível e pode ser entendido como “... a cena do poder e o lugar de todas as relações...” (RAFFESTIN, 1993, p. 59). Isto inclui todas as dimensões e interesses possíveis, sejam eles econômicos, políticos, sociais, religiosos e culturais que no conjunto formam arranjos multidisciplinares. Raffestin afirma esta visão quando menciona que 
O território se forma a partir do espaço, é o resultado de uma ação conduzida por um ator sintagmático (ator que realiza um programa) em qualquer nível, ao se apropriar de um espaço concreto ou abstratamente (por exemplo, pela representação) o ator "territorializa" o espaço. (1993, p.144)

Numa visão deste tipo, o território não representa simplesmente um espaço de contêiner, contudo, resulta de uma produção espacial relacional, baseado em relações de trabalho, de comunicação, de emoções etc. O espaço é, assim, nas palavras de Raffestin, uma “... prisão original e o território é a prisão que os homens constrói para si” (1993, p.144). Neste jogo, o território pode ser visto como um elemento da organização social, um trunfo de poder, um meio pelo qual ele se realiza (RAFFESTIN, 1993, p.59).

A partir desta noção, Raffestin ressalta a função da "territorialidade". Esta é um conglomerado múltiplo do "vivido" territorial pelos membros de um grupo social ou de uma sociedade (1993, p. 159). Conseqüentemente, as relações, cada uma com seu caráter específico, apresentam características culturais diferenciadas. Algumas podem ser relações discursivas, outras sígnicas, outras podem resultar numa coerção física, etc. No conjunto, estabelece-se uma tríade de territorialidade, uma função cultural. Esta mediatiza

1.) o indivíduo com o seu grupo e seu espaço através da definição da

2.) exterioridade, do espaço-fora, e da interligação para com o território,

3.) do espaço-próprio.

Esta mediação torna-se o posicionamento identitário. O lugar do próprio, aqui o território, pode ser abstrato ou definido, político ou cultural, mas sempre necessita de uma forma e de um conteúdo específico os quais o ligam com a exterioridade (1993, p. 160).

Assim, esse esquema aplicado à algumas realidades com grupos identitários distintos pode demonstrar "... um conjunto de relações que se originam num sistema tridimensional sociedade-espaço-tempo...” (RAFFESTIN, 1993, p. 160). Esse conjunto é composto por relações dinâmicas, mas assimétricas entre pólos distintos (RAFFESTIN, 1993, p. 161).

Para que se entenda uma dada territorialidade como elemento cultural é ainda necessário compreender a idéia do sujeito e com quais atos culturais o sujeito desenvolve-se no seu território (RAFFESTIN, 1993, p. 162). Indo além da concepção de Raffestin, a qual não discute as diferentes concepções do sujeito, precisamos mencionar, neste contexto, que 
existem culturas onde o sujeito é visto de forma idealizada como um indivíduo absoluto, enquanto outras dão enfoque maior nas sociabilidades e no grupo social.

Para a configuração do sujeito, Raffestin apresenta, como outros autores, a territorialidade apenas sob o enfoque simbólico. Menciona, sim que este elemento se apóia em referenciais materiais - fixas no território, mas que este sentimento do Eu utiliza os símbolos como um meio, um trunfo, pois "o ideal do poder é jogar exclusivamente com os símbolos" (RAFFESTIN, 1993, p. 60), e não como um elemento da produção. Símbolos, para ele podem ser entendidos como significados não fixos no território, mas que os criam, dominam e usam na comunicação social, criam, dominam e utilizam basicamente relações de poder para fins materiais, para garantir um poder maior. Entretanto, os símbolos formam a existência do sujeito e a esfera que o circunda.

Assim, a territorialidade “... adquire um valor bem particular, pois reflete a multidimensionalidade do 'vivido' territorial pelos membros de uma coletividade, pelas sociedades em geral" (RAFFESTIN, 1993, p. 158). Cada sociedade e cada grupo social necessita, neste sentido, de elementos de comunicação e reflexão que reproduzem as suas relações sociais em forma resumida. Esta virtualidade do vivido no simbólico-material permite o trânsito do processo territorial nas mais diversas escalas. Logo, "a territorialidade se manifesta em todas as escalas espaciais e sociais" (RAFFESTIN, 1993, p. 161) e torna-se uma "face" do poder, cujo rosto só ganha visibilidade quando se exprime no "imaginário" (p. 162).

Portanto, Raffestin deixa claro que o território é formado pela vivência das pessoas o que se expressa nas relações simbólicas-significativas. Estas estabelecem um vínculo (positivo ou negativo) para com o território através de territorialidades específicas. A partir do momento em que diferentes grupos se encontram, estas territorialidades se confrontam e estabelecem, por causa das suas tensões de diversidade, um campo de forças. Este resulta de relações de poder entre elas. Ganhar nova visibilidade para novas relações sociais significa, por isso, adequar a situação em combinando os espaços de origem, em base de simbologias inovadoras, para uma nova coesão social e territorial. 


\section{AGENCIAMENTO E AÇÃO NO TERRITÓRIO - AS ABORDAGENS DE GILLES DELEUZE/FELIX GUATTARI E ANTHONY GIDDENS}

A visão de Raffestin, especificamente da territorialidade, indica claramente um caminho em direção à geografia social e cultural. Por isto, contextualizamos esta abordagem agora não mais na geografia política, mas na geografia social e cultural.

O termo geografia cultural aparece no fim do século XIX na Europa, em meio a discussão sobre a identidade da ciência geográfica. Nesta época, a geografia era vista principalmente de um ângulo econômico e histórico, como demonstra Ratzel em sua obra "A geografia cultural dos Estados Unidos da América do Norte com ênfase especialmente voltada para as suas condições econômicas" (CLAVAL, 2001, p.20). Entretanto, já Ratzel discutia nesta obra os encontros culturais dentro de uma sociedade, se referindo às migrações globais e as conseqüentes transformações e dominações no espaço. Neste sentido, chamou atenção específica à questão dos imigrantes chineses nos Estados Unidos (CLAVAL, 2001, p.20).

Mas, a geografia cultural da época girava geralmente em torno de uma cultura material, portanto, se referia apenas às transformações que os moradores (residentes e migrantes) causavam na paisagem. No entanto, com a evolução da própria ciência geográfica que acompanhou as novas relações sociais no espaço na fase da industrialização e das migrações internacionais, numa sociedade moderna e complexa, a geografia cultural também passou por transformações. Assim, a geografia cultural na segunda metade do século XX começa colocar o homem, e não mais a paisagem e o território, no centro de suas análises beneficiando-se de diferentes bases filosóficas como a fenomenologia, o existencialismo e o idealismo.

Nesta ocasião, o território apresenta-se mais como um conceito de dimensão cultural/simbólica e subjetiva, pois "e pela existência de uma cultura que se cria um território e é por ele que se fortalece e se exprime a relação simbólica existente entre cultura e espaço" (BONNEMAISON, 2002, p. 101-102). Destarte, ressurgem ao nível espacial as relações entre sujeito, grupo social, etnia, cultura e espaço como assunto principal de uma geografia que pesquisa espaços particularizados num mundo globalizado.

Este caráter aglutinador do território ultrapassa, desta maneira, os limites das definições ideológicas, como classes, conceito de individualidade etc. Apresentam igualmente dimensões simbólicas como materiais desenvolvendo uma epistemologia abrangente, assim que a sua 
aplicação permite análises em diferentes versões culturais do espaço e do território, sempre baseados na ação e nas práticas sociais que o constituem.

Assim, a dupla face do território, a significativa e a material, se estabelece como relações sistêmicas da sociedade que se estruturam junto com as relações vividas e pessoais. De acordo com Guattari e Rolnik (apud HAESBAERT, 2004, p. 121)

O território pode ser relativo tanto a um espaço vivido quanto a um sistema percebido no seio da qual um sujeito se sente "em casa". O território é sinônimo de apropriação, de subjetivação fechada sobre si mesma.

Esta referência ao espaço vivido como território fica mais clara quando induzimos o termo do agenciamento (DELEUZE/GUATTARI 1995, p. 29/30, 1997, 218-220) como fator construtivo do e no território. Os chamados agenciamentos são as junções de ações no território podendo estar vinculadas ao desejo ou ao pensamento (HAESBAERT, 2004, p. 124). Assim, um território dinâmico coloca o desejo como elemento fundador dos fatores corporais, enquanto os agenciamentos das enunciações (como a língua, as expressões verbais, as leis, as idéias) surgem na sua dimensão simbólica. No entanto, vale ressaltar que esse encontro de diferentes âmbitos no território sempre se modifica, pois nem sempre as relações de poder estão atreladas ao mero desejo. No caso da territorialidade à vontade de pertencer a um dado lugar, muito embora sejam parcialmente fundamentais para a construção do território, muitas vezes é predefinida, como no caso da nacionalidade. Assim, pensamentos e sistemas ideológicos, como fator objetivo e premeditado, também podem influenciar na configuração de um território.

A questão do desejo e do pensamento remete de novo a Anthony Giddens (2003, p.116). Este sociólogo coloca que a ação como prática social é presente na conduta humana e pode ser premeditada na racionalização ou não, assim que o pensamento e o desejo não sempre coincidem. Desse modo, o desejo representa a intencionalidade (impulsivo, emocional) e a subjetividade, um elemento virtual, enquanto o pensamento representa o agir, um comportamento corporal representando a objetividade. Assim, a questão da objetividade está se cruzando no agenciamento apresentando uma "tetravalência" (DELEUZE/GUATTARI 1995, p. 30). Corpos cheios de desejos para funcionar como máquinas, que não são controladas por reflexões (agenciamento maquínico) e pensamentos, "transformações incorpóreas sendo atribuídos aos corpos" (agenciamentos coletivos de 
enunciação) (DELEUZE/GUATTARI 1995, p. 29). Ambos estão responsáveis para o entrelaçamento do território.

Esta dinâmica tetravalente revela o território como um espaço de ação, onde se realiza o subjetivo (intencional) e o objetivo (racional), construindo relações de poder com estrutura social (inter-objetiva) e estrutura cultural (inter-subjetiva). Para Anthony Giddens (2003, p. 17), o poder aborda desta maneira a capacidade de escolher, a capacidade transformadora. Neste sentido, a ação no território incorpora, sim, o desejo como fundador dos sistemas corporais, mas estabelece um sistema de controle na estruturação reflexiva embutida na língua e outros sistemas simbólicos. É evidente, que esta diferenciação é apenas teórica, enquanto os agenciamentos sempre reúnem todas as dimensões.

Esta mesma idéia também aparece em Raffestin (1993, p.59/60), quando destaca relações de poder como definidas por desejos (de pertencimento) e pensamentos (de nascimento) num campo de forças (psicológicas e econômicas-sociais). Assim, as populações e os recursos (tanto alocativos como autoritativos, conforme Giddens, e tanto materiais como simbólicos, conforme Haesbaert) caracterizam-se pela propriedade (como pertences e características) de um trunfo do poder, um meio do qual o poder se utiliza e permeia. De maneira que, "o território é o espaço político por excelência, o campo de ação dos trunfos" (RAFFESTIN, 1993, p. 60).

\section{CONSIDERAÇÕES FINAIS}

Desse modo vê-se que as concepções de Guattari e Deleuze(1995, 1996, 1997), Giddens (1991, 2003) e do próprio Raffestin (1993) se perpassam, todos destacando tanto o caráter racional, institucional, fixo, quanto o caráter simbólico, do desejo, da intenção, do vivido, presentes nas práticas e relações sociais que criam o território. Assim, Raffestin destaca o "poder" com fio condutor, Giddens a "ação" e Guattari Deleuze "o desejo e o pensamento".

Estas características ganham importância na atualidade, pois quando se menciona a possibilidade de haver um território fruto de uma mistura de identidades ou ainda da sobreposição de identidades, não se faz referência apenas aos aspectos culturais-simbólicos dessas identidades, mas também à organização social das ações manifestadas no cotidiano, e a organização dos pensamentos e desejos que as diferentes identidades estabelecem no 
território. A idéia da ação pode ser mais formal ou menos formal, mais direcionada ou menos direcionada, como também pode se modificar a idéia ou que é um desejo ou poder.

Assim, a criação de um território por grupos em conjunto implica sempre uma organização das suas relações sociais que podem estar vinculadas tanto aos aspectos materiais, fixos no território quanto aos simbólicos, que na maioria das vezes permeiam os espaços fixos.

Nesse sentido, Haesbaert tem razão quando afirma que “... não há qualquer atividade, inclusive atividades materiais, que não seja ao mesmo tempo produtora de sentido e de símbolos..." (2004, p. 214). Portanto, é sob a perspectiva significativa-material, no qual age o agenciamento "desejo-pensamento", e a interação entre intenção e modo de agir, que o conceito de território foi discutido no presente artigo.

Neste contexto, os grupos definem e constroem as suas relações entre eles e frente do Estado, como formas culturais inclusive com as suas respectivas dinâmicas. Assim, apesar de que se destaca a característica cultural na dinâmica territorial, a dimensão material no território não pode ser descartada em situações de ordem econômica e/ou política, porque ela também é um produto pensado e cultural.

\section{RERERÊNCIAS BILIOGRÁFICAS}

BOLIGIAN, Levon; ALMEIDA, Rosângela Doin de. A transposição didática do conceito de território no ensino de geografia. In: Ambientes: estudos de geografia. (org) Lúcia Helena de Oliveira Gerardi. Rio Claro: Programa de Pós-graduação em Geografia - UNESP; Associação de Geografia teorética - AGETEO, 2003. p. 235-248.

BONNEMAISON, Joel. Viagem em torno do território. In: Geografia cultural:um século (3). (Orgs) Roberto Lobato Corrêa; Zeny Rosendahl. Rio de Janeiro:EdUERJ, 2002, p. 83132.

COSTA, Wanderley Messias da. O Estado e as políticas territoriais no Brasil. São Paulo: Contexto, 1991.

CLAVAL, Paul. A geografia cultural. Tradução: Luiz Fagazzola Pimenta; Margareth de Castro Afeche Pimenta. $2^{\mathrm{a}}$ edição. Florianópolis: Ed. Da UFSC, 2001.

DELEUZE, G. e GUATTARI, F. Mil Platôs: capitalismo e esquizofrenia. Vol. 2. Rio de janeiro: Editora 34, 1995.

Mil Platôs: capitalismo e esquizofrenia. Vol. 3. Rio de janeiro: Editora 34, 1996. 
Mil Platôs: capitalismo e esquizofrenia. Vol. 5. Rio de janeiro: Editora 34, 1997.

DERRIDA, Jacques. La différance, In: Marges de la Philosophie. Les Éditions de Minuit, Paris. Tradução para o português de Joaquim Torres Costa e António M. Magalhães. A Diferença. In: Margens da Filosofia, Papirus Editora, 1991, Campinas, São Paulo - Brasil, pp. $33-63$.

DI MÈO, Guy. Géographie sociale et territoires. Tradução para o português Wolf- Dietrich SAHR, Paris: Nathan, 1998.

FOUCAULT, Michel. Microfísica do poder. (Org). Tradução: Roberto Machado. $1^{\mathrm{a}}$ edição. Rio de janeiro: Edições Graal, 1979.

GIDDENS, Anthony. A constituição da sociedade. Tradução: Álvaro Cabral. São Paulo: Martins Fontes, 2003.

HAESBAERT, Rogério. Identidades territoriais. In: Manifestações da cultura no espaço. ROSENDAHL, Zeny; CORRÊA, Roberto Lobato. (Orgs). Editora UERJ. Rio de janeiro: 1999b, p. 169-190.

O mito da desterritorialização: do 'fim dos territórios' à multiterritorialidade. Rio de janeiro: Bertrand Brasil, 2004.

HARVEY, David. A condição pós-moderna. São Paulo. Loyola. 1992.

JAMENSON, Frederic. A lógica cultural do capitalismo tardio. São Paulo. Ed. Ática.1996.

MORAES, A.C.R. Geografia: pequena história crítica. 16 ed. São Paulo, Hucitec, 1998.

RAFFESTIN, Claude. Por uma Geografia do Poder. Tradução: Maria Cecília França. São Paulo: Ática, 1993.

SANTOS, M. O retorno do território. In: SANTOS, M.; SOUZA, M.A.A.; SILVEIRA, M.L. (Org.) Território: globalização e fragmentação. São Paulo, Hucitec/ANPUR, 1994.

SANTOS, M. Por uma outra globalização: do pensamento único à consciência universal. $2^{a}$ edição. Rio de Janeiro/São Paulo, Record, 2000.

SILVA, Carla Holanda da. Território e identidade cultural: a possível presença de uma rede em Assaí - PR. Monografia de conclusão de curso. (Bacharelado em Geografia). UEL. Londrina, 2005, p. 1-99.

VALVERDE, R.R.H.F. Transformações no conceito de território: competição e mobilidade na cidade. Geousp - Espaço e Tempo. São Paulo, n.115, 2004, p.119-126.

VIRILO, Paul. O espaço Crítico. Rio de janeiro: ED. 34, 1993.

(Recebido em setembro/08. Aceito em maio/09) 